07

\title{
Влияние состояния внутренних границ раздела на характер разрушения гранита при квазистатическом сжатии
}

\author{
() Е.Е. Дамаскинская ${ }^{1}$, И.А. Пантелеев ${ }^{2}$, А.Г. Кадомцев ${ }^{1}$, О.Б. Наймарк ${ }^{2}$ \\ ${ }^{1}$ Физико-технический институт им. А.Ф. Иофрфе РАН, \\ Санкт-Петербург, Россия \\ ${ }^{2}$ Институт механики сплошных сред УрО РАН, \\ Пермь, Россия \\ E-mail: Kat.Dama@mail.ioffe.ru
}

(Поступила в Редакцию 3 октября 2016 г.)

\begin{abstract}
На основе анализа пространственного распределения гипоцентров источников сигналов акустической эмиссии и анализа распределений сигналов акустической эмиссии по энергии исследуется влияние жидкой фазы и воздействия внешнего слабого электрического поля на пространственно-временно́й характер разрушения гранитных образцов. В экспериментах по одноосному сжатию образцов гранита естественной влажности показано, что процесс накопления повреждений является двухстадийным: дисперсное накопление повреждений сменяется стадией локализованного накопления повреждений в зоне формирующегося очага макроразрушения. На энергетических распределениях сигналов акустической эмиссии этот переход сопровождается сменой формы распределения с экспоненциальной на степенную. Водонасыщение гранита качественно меняет характер накопления повреждений: вплоть до макроразрушения процесс накопления является делокализованным с экспоненциальной формой распределения сигналов акустической эмиссии по энергии. Воздействие слабого электрического поля приводит к избирательному изменению характера накопления повреждений в объеме образца.
\end{abstract}

Работа выполнена при финансовой поддержке РФФИ (гранты № 16-05-00237, 16-41-590779-р_урал_а).

DOI: 10.21883/FTT.2017.05.44381.364

\section{1. Введение}

Интенсивные исследования в области физики и механики прочности структурно-неоднородных хрупких материалов, проводимые в последние 30-40 лет, позволили существенно продвинуться в понимании закономерностей накопления повреждений и формирования очага макроразрушения. Общей особенностью накопления дефектов при деформировании таких структурнонеоднородных материалов, как горные породы, керамики, стекло- и углепластики, является наличие двух характерных стадий процесса [1-4]. Первая стадия процесса накопления повреждений характеризуется низкой, слабо изменяющейся интенсивностью роста количества дефектов во всем объеме деформируемого материала. Вторая стадия - стадия интенсивного роста поврежденности (количества дефектов) в узкой пространственной зоне области формирующегося очага макроразрушения. Разработка методов прогнозирования разрушения структурно-неоднородных материалов в широком диапазоне пространственных масштабов, а также методов оценки степени критичности текущего состояния таких материалов приводит к необходимости поиска предвестников перехода от первой стадии накопления повреждений ко второй. Сложность решения этой задачи заключается в том, что в большинстве случаев не существует четкой границы между двумя указанными стадиями. Постепенная локализация процесса накопления повреждений в выделенной пространственной об- ласти может проходить на фоне равномерного образования дефектов во всем объеме материала. В настоящее время решению этой задачи посвящено множество исследований, направленных на всестороннее изучение процессов, сопровождающих накопление повреждений, различными разрушающими и неразрушающими методами [5-18]: ультразвуковым методом, методами акустической и электромагнитной эмиссии, фрактолюминесценции, нейтронной эмиссии, оптической и электронной микроскопии и др.

Несмотря на достигнутый прогресс в исследовании предвестников перехода от стадии дисперсного накопления повреждений к стадии формирования очага макроразрушения, вопрос о физических механизмах такого перехода и факторах, на него влияющих, до сих пор остается открытым. Ранее в работах [1,2,19-22] было показано, что переход между двумя стадиями обусловлен достижением плотностью дефектов (трещин) в деформируемом материале критической величины, после которой дефекты начинают взаимодействовать между собой упругими полями. Значение критической плотности дефектов варьируется в широких пределах и определяется исходной дефектной структурой материала, его механическими свойствами и условиями нагружения. Согласно [23], двумя предельными случаями такого взаимодействия являются экранирование и усиление полей напряжений. Коллективное поведение (взаимодействие) дефектов в структурно-неоднородных хрупких телах при их деформировании не зависит от 
масштаба взаимодействующих дефектов, а определяется, как показано в работе [24], величиной концентрационного параметра, представляющего собой отношение двух характерных пространственных масштабов в ансамбле дефектов: среднего размера дефекта и среднего расстояния между дефектами. Таким образом, процесс накопления повреждений в хрупких телах имеет самоподобный характер в широком диапазоне масштабов (от лабораторного масштаба до геологического). Самоподобие процесса накопления повреждений в структурнонеоднородных средах проявляется в выполнении ряда закономерностей: закона повторяемости (степенных распределений) для энергий (магнитуд) сигналов акустической эмиссии (АЭ) и сейсмических событий $[18,25,26]$, степенных распределений блоков, активных разломов и трещин в лабораторных образцах [26-29] по размерам. Опыт использования концентрационного параметра для решения задач прогнозирования разрушения (перехода ко второй стадии накопления повреждений) [30] показал, что данный подход имеет ряд недостатков. Результат оценки величины концентрационного параметра зависит от чувствительности используемой системы регистрации АЭ, уровня шумов в измерительных каналах, степени исходной неоднородности материала. Влияние обозначенных факторов проявляется в существенной вариации критической величины концентрационного параметра в зависимости от материала и размеров объекта мониторинга, в отсутствии явно выраженного порога на зависимости концентрационного параметра от времени деформирования. В этом случае определение момента перехода объекта мониторинга в предразрушающее состояние весьма затруднено либо определяется с запозданием.

В соответствии с описанным выше механизмом переход от первой стадии накопления повреждений ко второй в конкретном материале контролируется интенсивностью образования новых дефектов и ростом существующих трещин. В свою очередь интенсивность трещинообразования, согласно классической механике разрушения, контролируется двумя энергетическими параметрами: потенциальной энергией деформации и удельной поверхностной энергией. При неизменной величине потенциальной энергии деформации вариация величины удельной поверхностной энергии должна приводить к изменению характера трещинообразования вплоть до вырождения стадии локализации. Изменение характера трещинообразования в этом случае будет сопровождаться нарушением указанных степенных закономерностей. Подтверждением этого являются результаты анализа распределений энергий сигналов акустической эмиссии при деформировании образцов горных пород и энергии горных ударов, зарегистрированных на территории действующего горнодобывающего предприятия, опубликованные в работах $[31,32]$. Показано, что стадии дисперсного (равновероятного по пространству и некоррелированного) накопления повреждений соответствует экспоненциальная форма энерге- тического распределения, тогда как стадии локализации (коррелированного дефектообразования) в районе формирующегося очага макроразрушения соответствует степенное распределение сигналов по энергии. Данный подход использован в настоящей работе для определения характера накопления повреждений (дисперсный, локализованный) при деформировании гранитных образцов.

Среди множества факторов, влияющих на удельную поверхностную энергию, применительно к задачам разрушения структурно-неоднородных материалов, в частности горных пород, особенно значимыми являются наличие жидкой фазы на внутренних границах раздела (берегах трещин, границах кристаллитов и т.д.) или изменение поверхностной плотности заряда на этих границах под действием внешнего электрического поля.

В работах $[33,34]$ показано, что инжекция на поверхность деформируемого образца малого (по сравнению с его объемом) объема жидкости приводит к интенсификации процесса трещинообразования, сопровождающегося всплеском АЭ. Другим подтверждением влияния флюида на процесс разрушения структурно-неоднородных материалов являются экспериментально установленные зависимости предела прочности образцов кварцевого диорита от величины дзета-потенциала и ионной силы насыщающего образцы флюида [35,36].

В случае воздействия на нагруженные диэлектрики слабого электрического поля в работах [37-39] установлено, что отклик АЭ во время сеанса воздействия наблюдается вне зависимости от степени влагонасыщенности образцов, минерального состава, наличия минераловпьезоэлектриков при уровне приложенного механического напряжения более $50 \%$ от предела прочности. При этом проведенные в [40] оценки показывают, что ни один из известных механизмов прямого преобразования электрической энергии в механическую не может обеспечить величину энергии, выделяющуюся в виде АЭ. В работе [41] на основе лабораторного моделирования показано, что слабое электромагнитное воздействие может служить триггером для инициирования подвижки в модели stick-slip. Еще одним подтверждением тесной взаимосвязи внешнего электрического воздействия и процесса накопления повреждений в геосреде является установленный по скважинным измерениям эффект модуляции геоакустической эмиссии внешним электромагнитным излучением [42-44].

Настоящая работа посвящена исследованию влияния жидкой фазы или воздействия внешнего непрерывного слабого электрического поля на пространственновременно́й характер разрушения гранитных образцов по данным, полученным методом АЭ. Акцент в работе сделан на изучении стадийности процесса накопления повреждений с помощью анализа данных локации источников (пространственных распределений координат гипоцентров источников) АЭ и распределений числа сигналов АЭ по энергии. 


\section{2. Материал и методика экспериментов}

В качестве модельного материала для проведения экспериментальных исследований влияния состояния внутренних границ раздела на процесс накопления повреждений был выбран гранит двух месторождений: Вестерли (США) и Мансуровский (Башкирия, Россия). Для исключения влияния условий деформирования на результаты исследований были проведены два вида экспериментов по квазистатическому сжатию образцов гранита: деформирование в условиях управляемого режима нагружения и одноосное сжатие. Данные эксперименты являлись опорными для дальнейшего анализа влияния жидкой фазы или внешнего воздействия слабого электрического поля на характер разрушения гранитных образцов.

Эксперименты в условиях управляемого режима нагружения проводились на серво-гидравлической установке, имеющей обратную связь [3]. Прикладываемая осевая нагрузка изменялась таким образом, чтобы активность сигналов АЭ с амплитудой выше пороговой не превышала заранее установленного уровня. Образцы гранита Вестерли имели форму цилиндра с размерами $h=190.5 \mathrm{~mm}, d=76.2 \mathrm{~mm}$ и деформировались в условиях постоянного всестороннего сжатия (давление $50 \pm 0.2 \mathrm{MPa})$ и одноосного осевого нагружения $\left(P_{\mathrm{ax}}\right)$. Процесс накопления повреждений во время эксперимента контролировался с помощью регистрации АЭ шестью пьезоэлектрическими преобразователями (резонансная частота $600 \mathrm{kHz}$ ), установленными на боковой поверхности образца. Точность определения координат гипоцентров источников АЭ составила $\sim 3 \mathrm{~mm}$.

На этой же установке [45] были проведены испытания водонасыщенных образцов гранита Вестерли с аналогичной аппаратурой регистрации АЭ, но без реализации обратной связи между машиной и системой регистрации АЭ. Насыщенный водой образец деформировался в условиях всестороннего сжатия (50 MPa), в процессе нагружения вода нагнеталась под давлением $1 \mathrm{MPa}$. Осевая деформация задавалась дискретными шагами, при этом измерялась осевая нагрузка.

Квазистатические испытания образцов Мансуровского гранита в условиях одноосного сжатия проводились на электромеханической машине Shimadzu AGX-Plus с максимальным усилием $30 \mathrm{t}$. Образцы имели форму цилиндра с размерами $h=95.5 \mathrm{~mm}, d=41 \mathrm{~mm}$. Ввиду отсутствия обратной связи между машиной и системой регистрации АЭ нагружение образцов осуществлялось со ступенчато изменяемой скоростью: до нагрузки $7.5 \mathrm{t}$ скорость нагружения составляла $0.03 \mathrm{~mm} / \mathrm{min}$, с 7.5 до $15 \mathrm{t}$ скорость нагружения была равна $0.015 \mathrm{~mm} / \mathrm{min}$, свыше $15 \mathrm{t}-0.0075 \mathrm{~mm} / \mathrm{min}$. Для непрерывного мониторинга акустической эмиссии в процессе деформирования была использована система Amsy-5 Vallen (Германия), укомплектованная антенной с восьмью датчиками: шестью широкополосными DECI SE2MEG-P (частотный

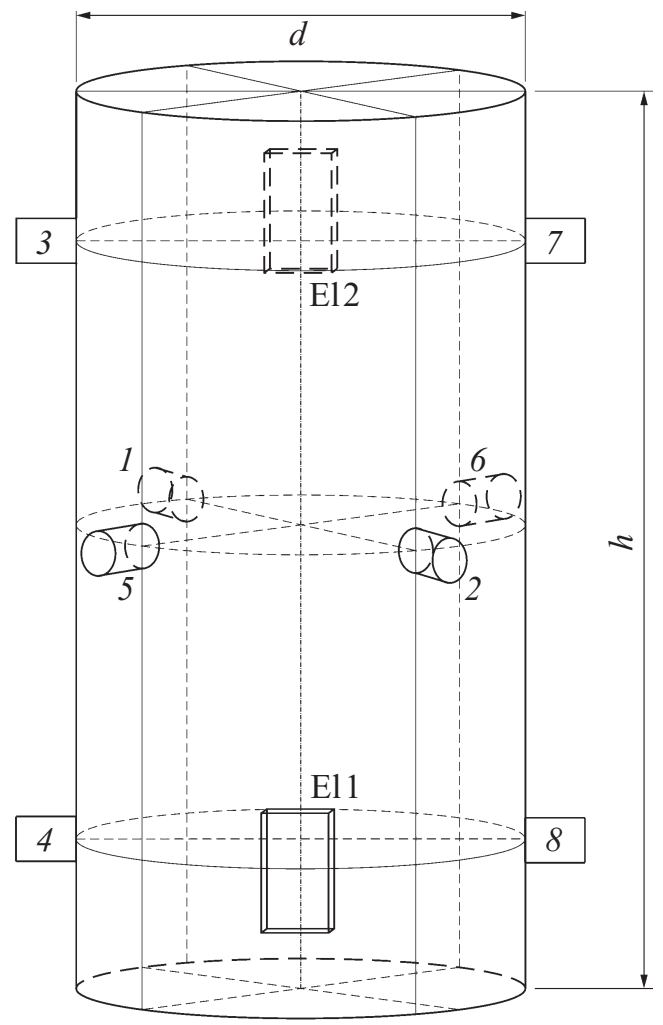

Рис. 1. Схема расположения электродов (E11, El2) и датчиков акустической эмиссии $(1-8)$ на боковой поверхности образца Мансуровского гранита.

диапазон 200-2000 kHz) и двумя датчиками AE105A $(450-1150 \mathrm{kHz})$. Точность определения координат гипоцентров источников АЭ составила $\sim 5.5 \mathrm{~mm}$.

Аналогичные условия нагружения были реализованы в экспериментах по квазистатическому одноосному сжатию образцов Мансуровского гранита естественной влажности с непрерывным (на протяжении всего эксперимента) воздействием слабого электрического поля. Для этого на графитовые электроды, прижатые к боковым поверхностям образца (рис. 1), подавалось напряжение в виде прямоугольных однополярных (положительной полярности) импульсов от генератора сигналов АКИП-3407/1А, усиленное при помощи Tabor 9400 с коэффициентом 50 (параметры импульсов следующие: напряжение $100 \mathrm{~V}$, частота $2.5 \mathrm{kHz}$, длительность $100 \mu \mathrm{s}$, скважность 25\%). Для улучшения электрического контакта между образцом и электродами на образец наносился толстый (порядка $2-3 \mathrm{~mm}$ ) слой проводящего графитового лака. В результате в процессе деформирования образец гранита подвергался непрерывному воздействию неоднородного (по пространству) переменного электрического поля, максимальная напряженность которого составляла $1 \mathrm{kV} / \mathrm{m}$.

В каждом из четырех типов экспериментов локация источников (определение координат гипоцентров источников) АЭ осуществлялась по разности времен прихода 

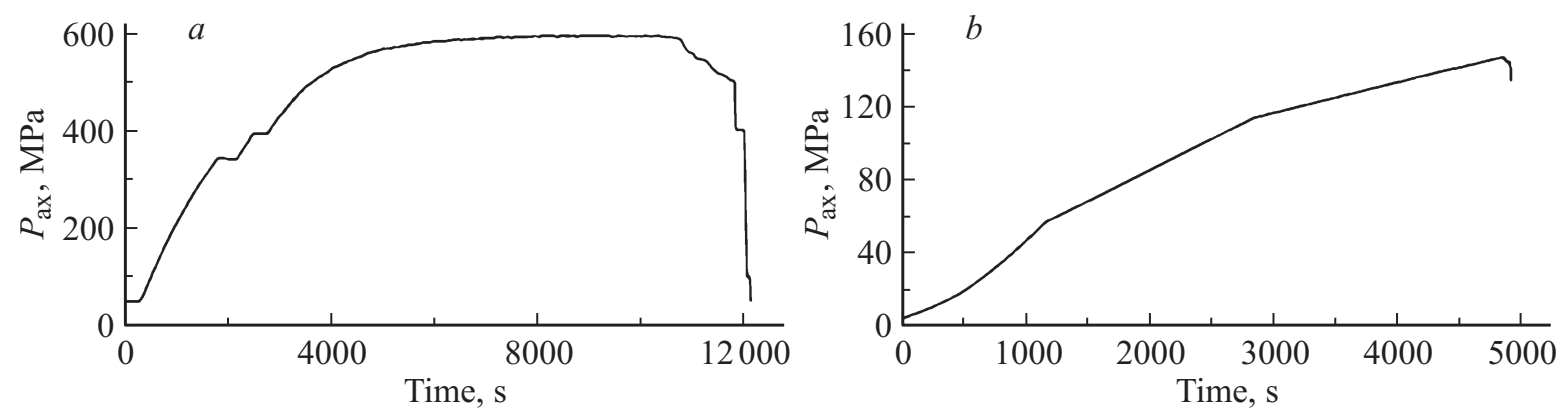

Рис. 2. Характерные диаграммы деформирования образца гранита Вестерли $(a)$ и образца Мансуровского гранита $(b)$.
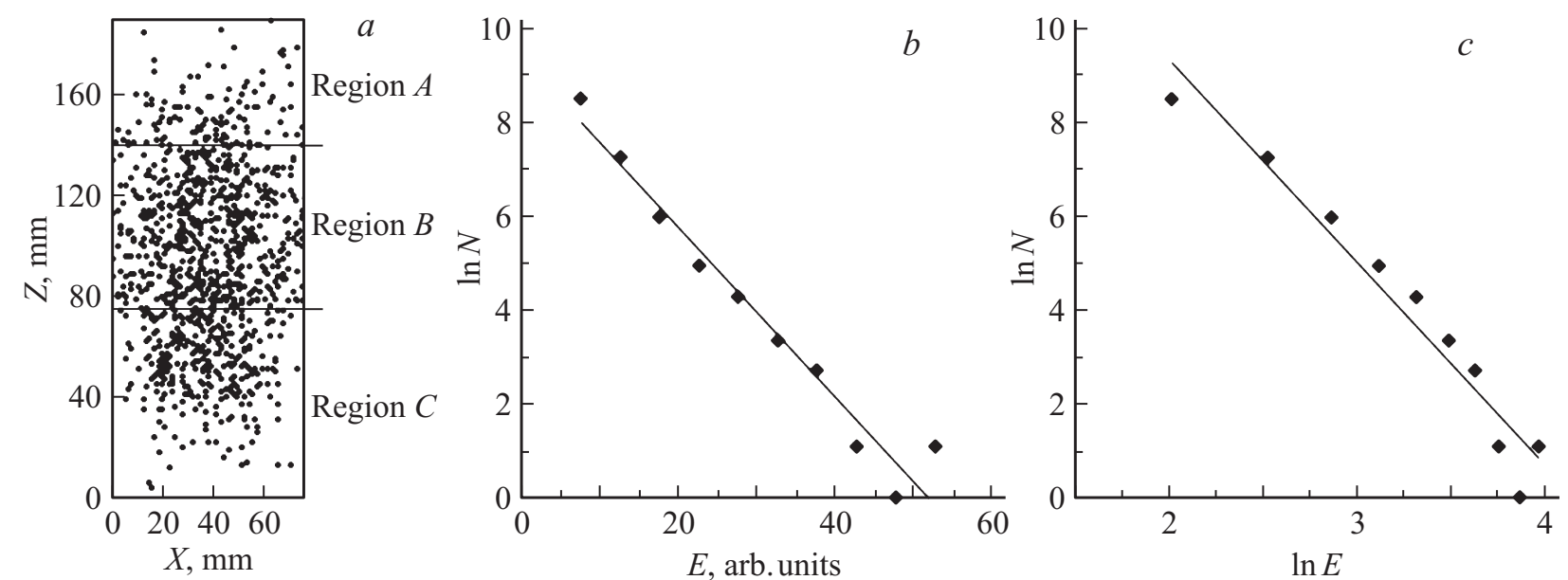

Рис. 3. Пространственный и энергетический анализ разрушения гранитных образцов. Проекции координат гипоцентров источников АЭ: $a$ - начальная стадия нагружения (АЭ-сигналы, зарегистрированные в период времени от начала нагружения до 0.6 долговечности образца); $b, c-$ распределения числа $N$ сигналов акустической эмиссии по энергии $E$.

сигналов АЭ на пьезоэлектрические преобразователи. Перед началом каждого эксперимента производилась оценка кривой затухания упругих волн в образце. Построенная кривая затухания далее использовалась для приведения амплитуды каждого сигнала АЭ к амплитуде в источнике. Важно отметить, что приведенная амплитуда не зависит от геометрии расположения пьезопреобразователей и может служить энергетической характеристикой АЭ сигнала.

\section{3. Результаты экспериментов}

3.1. Квазистатическое сжатие в условиях управляемого нагружения и одноосное сжатие гранита. На рис. 2 представлены характерные диаграммы нагружения образца гранита Вестерли в условиях управляемого нагружения $(a)$ и образца Мансуровского гранита при одноосном сжатии $(b)$. Применение обратной связи в виде управления скоростью нагружения по величине акустоэмиссионной активности позволяет растянуть во времени стадию, предшествующую макроразрушению, и довести деформирование образца до закритической стадии, характеризующейся ниспадающей ветвью на диаграмме деформирования.

Подробный пространственно-временно́й анализ развития разрушения в экспериментах по всестороннему сжатию образцов гранита Вестерли, проведенный ранее в работах $[46,47]$, показал, что разрушение происходит по двухстадийному механизму: сначала дефекты образуются дисперсно (хаотично) (рис. $3, a$ ), затем наблюдается локализация (рис. 4,a), формируется очаг, развитие которого приводит к макроразрыву. На рис. $3, a$ показано пространственное распределение координат гипоцентров АЭ-сигналов на начальной стадии нагружения ( 0.5-0.6 времени жизни образца). Распределения АЭсигналов по энергии можно с одинаковой погрешностью аппроксимировать как степенной, так и экспоненциальной функцией, что иллюстрирует рис. $3, b, c$, где данное распределение построено в полулогарифмических и двойных логарифмических координатах. Такая картина указывает на то, что в разных пространственных частях образца характер дефектообразования различный. Действительно, построение энергетических распределений сигналов АЭ для различных пространственных областей (по вертикали) позволяет определить области, в которых распределение аппроксимируется экспоненциальной 

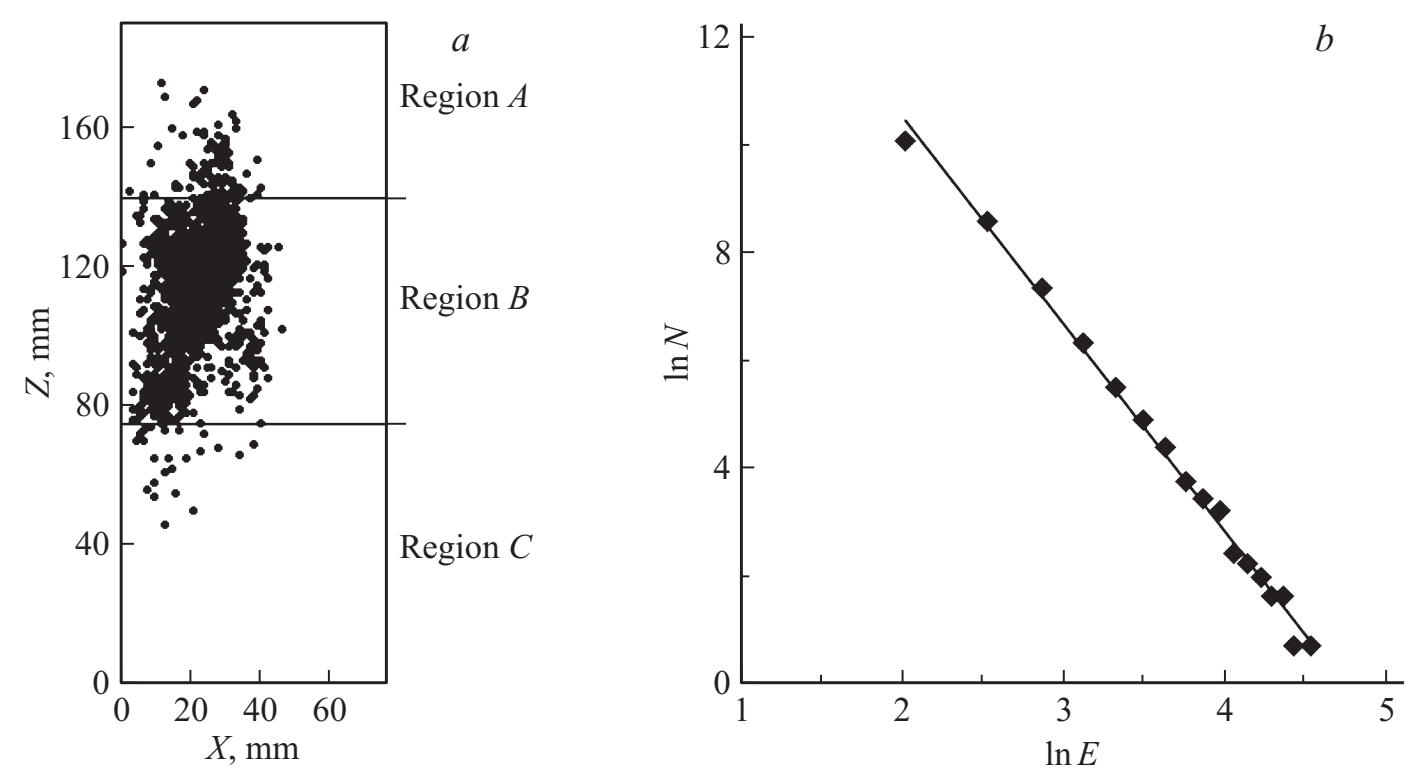

Рис. 4. Пространственный и энергетический анализ разрушения гранитных образцов (период времени от 0.9 долговечности вплоть до разрушения образца). $a$ - проекции координат гипоцентров источников АЭ, $b-$ распределение сигналов акустической эмиссии по энергии $E$.
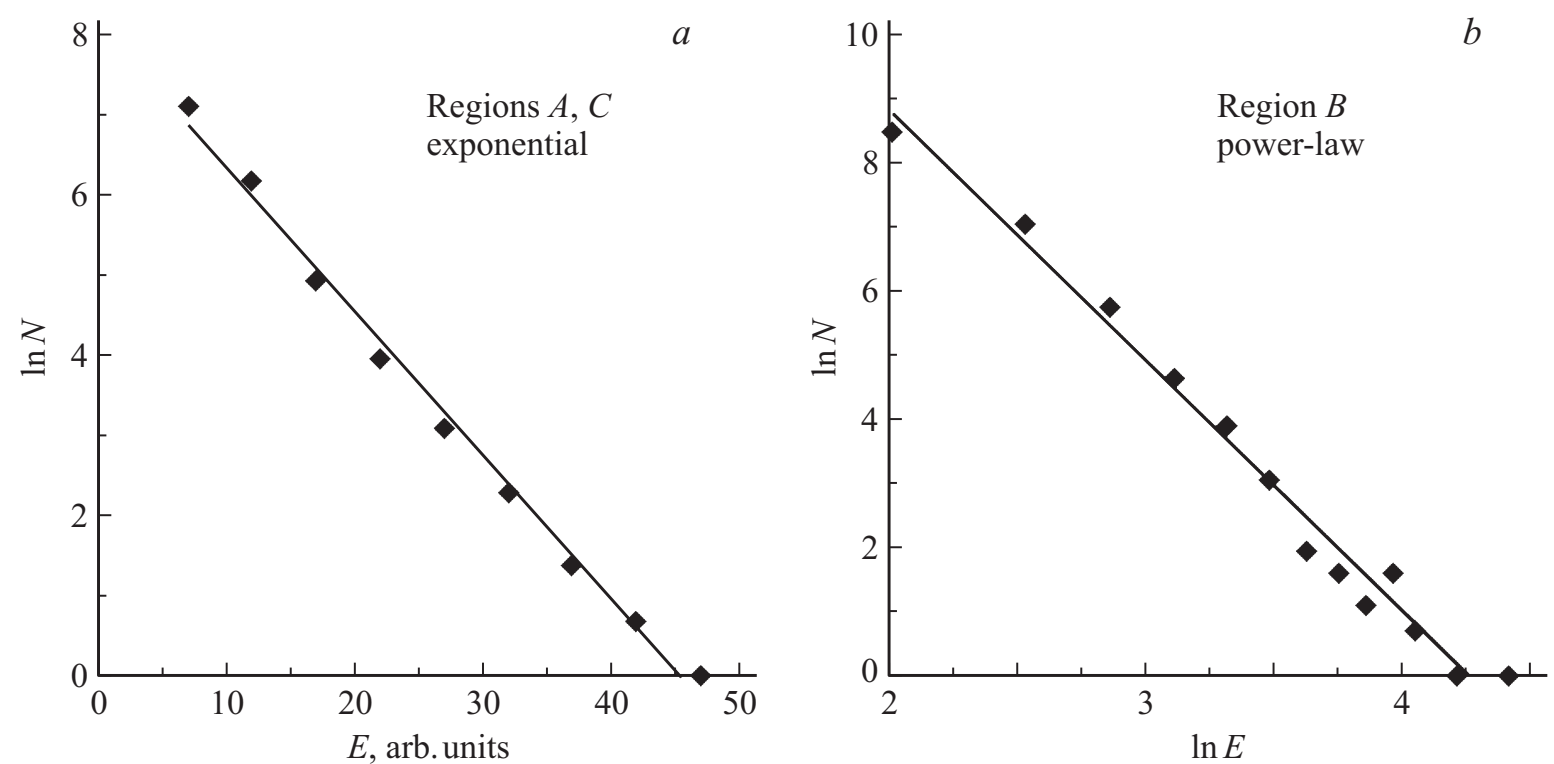

Рис. 5. Энергетический анализ разрушения гранитных образцов (период времени от начала нагружения до 0.6 долговечности образца). Распределения сигналов акустической эмиссии по энергии $E$, полученные в результате пространственного „сканирования“ образца. $a-$ области $A, C, b-$ область $B$.

функцией (рис. 5), и области, в которых распределение аппроксимируется степенной функцией.

На завершающем этапе деформирования наблюдается локализация дефектообразования (рис. 4, $a$ ) (наиболее отчетливо область локализации выявляется при анализе сигналов с относительно большими амплитудами). Распределение по энергии АЭ-сигналов имеет степенной вид (рис. $4, b$ ). Важно отметить, что локализация дефектообразования происходит именно в той пространственной области (область $B$ ), в которой еще на ранних этапах (при однородном пространственном распределении дефектов) энергетическое распределение имело степенной вид. Таким образом, анализ функционального вида энергетического распределения сигналов АЭ позволил выделить область будущего очага разрушения раньше, чем это удается сделать другими методами (например, по изменению фрактальной размерности пространственного расположения гипоцентров источников сигналов АЭ [18], дисперсии вейвлет-коэффициентов энергии) $[16,48]$. 

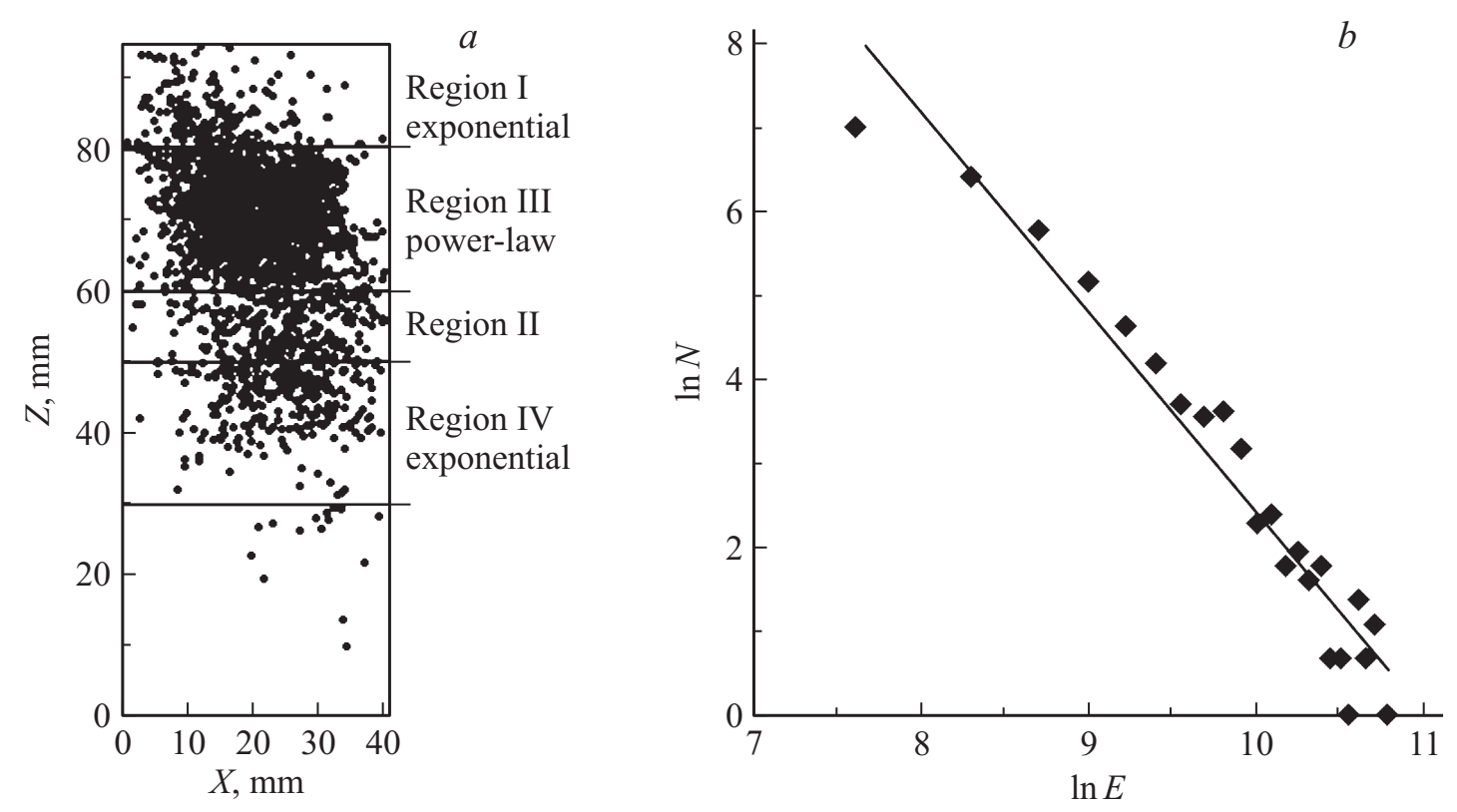

Рис. 6. Пространственный и энергетический анализ разрушения в эксперименте по одноосному сжатию образца Мансуровского гранита. $a$ - проекции координат гипоцентров источников АЭ, $b$ - распределение сигналов акустической эмиссии по энергии $E$.

Проекции гипоцентров источников всех сигналов АЭ, зарегистрированных при одноосном сжатии Мансуровского гранита, представлены на рис. 6. Из рисунка видно, что распределение гипоцентров имеет неравномерный характер. Неравномерное распределение вызвано рядом причин. Во-первых, чувствительность регистрирующей аппаратуры позволяла регистрировать АЭ не с самого начала нагружения, а только начиная с нагрузки $40-45 \%$ от предельного уровня. Во-вторых, деформирование Мансуровского гранита сопровождалось интервалами резкой активизации акустической эмиссии, источники которой были локализованы в некоторых пространственных областях.

Преимущественная локализация в выделенных пространственных областях повреждений при деформировании Мансуровского гранита отражается также в степенном виде распределения количества сигналов АЭ по энергии (рис. 6, $b$ ). При этом построение энергетического распределения сигналов АЭ для ряда вертикальных зон (рис. $6, a$ ) показало, что выделяются области I и IV, ограниченные по высоте координатами 80-95.5 и 30-50 mm (рис. 6,a), в которых распределение аппроксимируется экспоненциальной функцией (рис. 7,a). В этих областях дефекты образуются равномерно (хаотично). В области II, ограниченной высотами 50-60 mm (рис. 6, $a$ ), распределение сигналов АЭ по энергии можно с одинаковой погрешностью аппроксимировать как экспоненциальной, так и степенной функцией (рис. 7, c). Это указывает на то, что в некоторых объемах области II дефекты образуются хаотично (независимо друг от друга), а в других объемах локализованно (коррелированно). Провести более детальное пространственное сканирование области II не представляется возможным из-за недостаточной статистики. В области III $(60-80 \mathrm{~mm}$, рис. 6, $a)$ энергетическое распределение имеет степенной вид (рис. 7,b). Именно в этой области и наблюдается наибольшая плотность дефектов (в 6 раз выше, чем в областях I и IV, и в 3 раза выше, чем в области II), формируется очаг разрушения.

Проведенный анализ данных АЭ, зарегистрированной в экспериментах по деформированию в условиях управляемого режима нагружения гранита Вестерли и одноосному сжатию Мансуровского гранита, показал, что для обоих условий нагружения процесс накопления повреждений имеет стадию пространственной локализации. Область локализации гипоцентров источников АЭ (коррелированное дефектообразование) идентифицируется как по результатам решения задачи локации, так и по степенному виду распределения сигналов АЭ по энергии. А область дисперсного (некоррелированного) образования дефектов, которую не всегда удается выявить с помощью анализа пространственного распределения дефектов, можно идентифицировать по экспоненциальному виду функции энергетического распределения сигналов АЭ.

3.2. Деформирование водонасыщенных образцов гранита. На рис. 8 представлены графики изменения осевой нагрузки и активности АЭ в процессе деформирования водонасыщенного образца. Видно, что в момент ступенчатого увеличения нагрузки на образец наблюдаются всплески активности АЭ. Решение задачи локации показало, что в течение всего времени эксперимента образование дефектов происходило дисперсно (хаотично) во всем объеме образца (рис. 9, $a$ ). Подобное пространственное распределение наблюдалось как при 

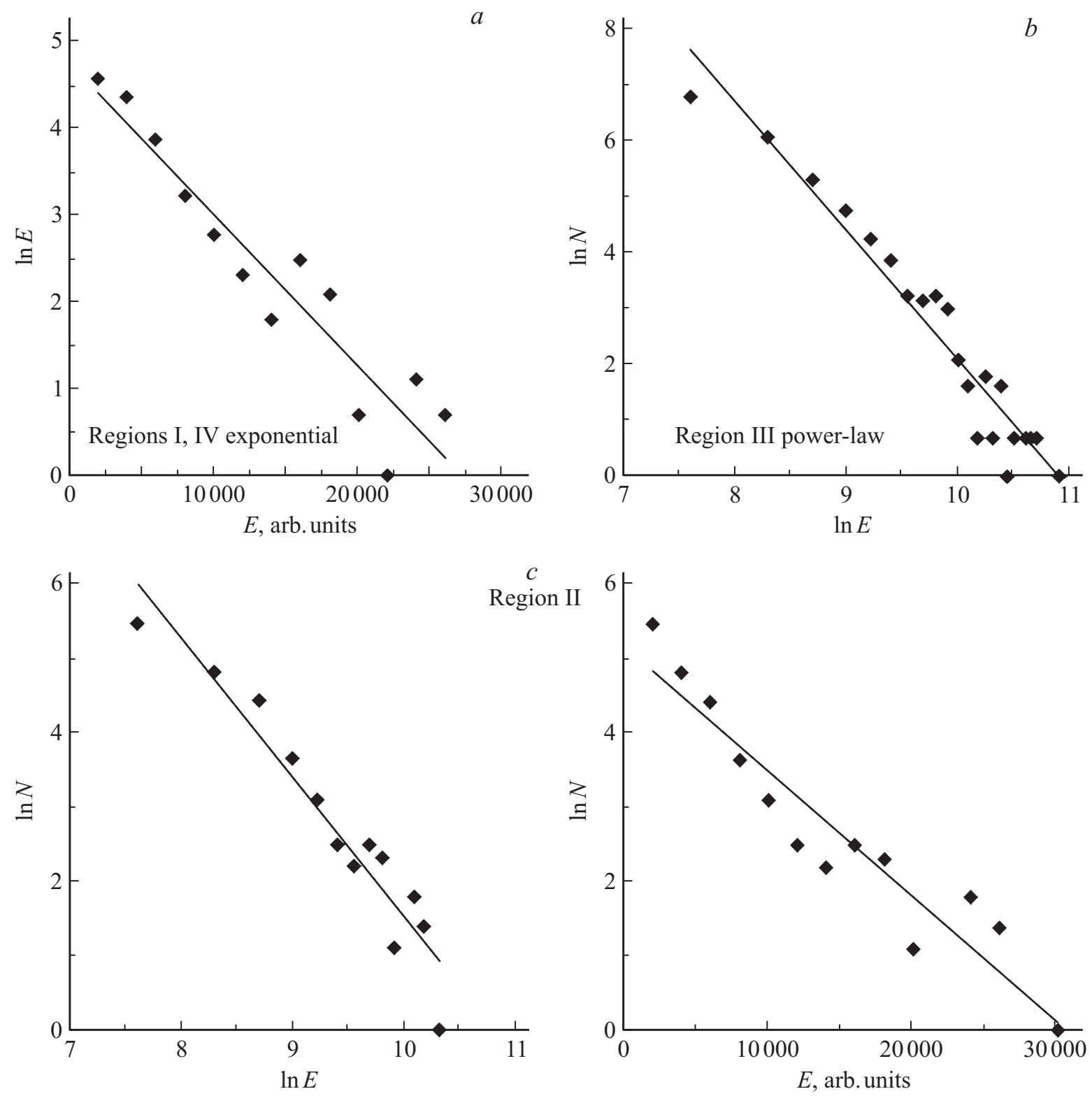

Рис. 7. Энергетический анализ разрушения в эксперименте по одноосному сжатию образца Мансуровского гранита, проведенный для различных пространственных областей. Пояснения приведены в тексте.

анализе АЭ-сигналов всех амплитуд, так и при анализе сигналов с амплитудами выше пороговой.

На делокализованный характер накопления повреждений в течение всего времени деформирования указывают также результаты анализа энергетических распределений сигналов АЭ. На протяжении всего эксперимента распределение сигналов АЭ по энергии, построенное для сигналов, зарегистрированных как во всем образце, так и в различных пространственных областях, имеет экспоненциальный вид (рис. 9, $b$ ). Таким образом, принудительное водонасыщение гранита при сжатии приводит к изменению характера накопления повреждений. Сравнение результатов механических испытаний образцов водонасыщенного гранита Вестерли и образцов гранита Вестерли естественной влажности показало, что водона- сыщение в целом сказывается и на прочностных характеристиках материала [49]: разрушение водонасыщенных образцов происходит при значительно меньшем уровне приложенной нагрузки.

3.3. Одноосное сжатие гранита с воздействием слабого электрического поля. В отличие от экспериментов по одноосному сжатию образцов Мансуровского гранита при непрерывном воздействии слабого электрического поля происходит изменение характера накопления повреждений. Распределение гипоцентров источников сигналов АЭ имеет более равномерный характер (рис. 10). При этом существенного изменения механических или прочностных характеристик в случае воздействия электрического поля не наблюдается. Распределение всех зарегистриро- 


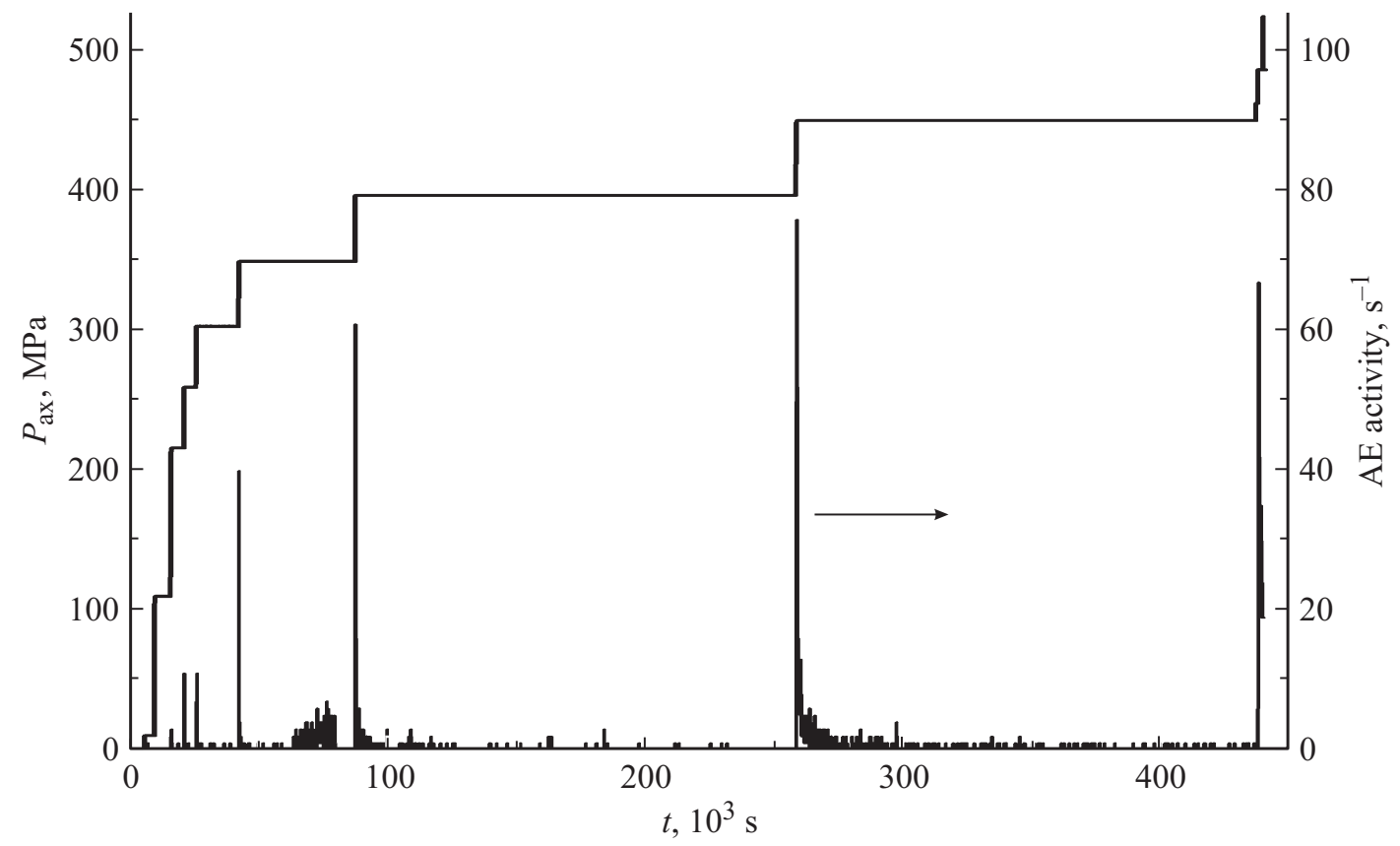

Рис. 8. Графики изменения осевой нагрузки и активности АЭ в процессе деформирования водонасыщенного образца.
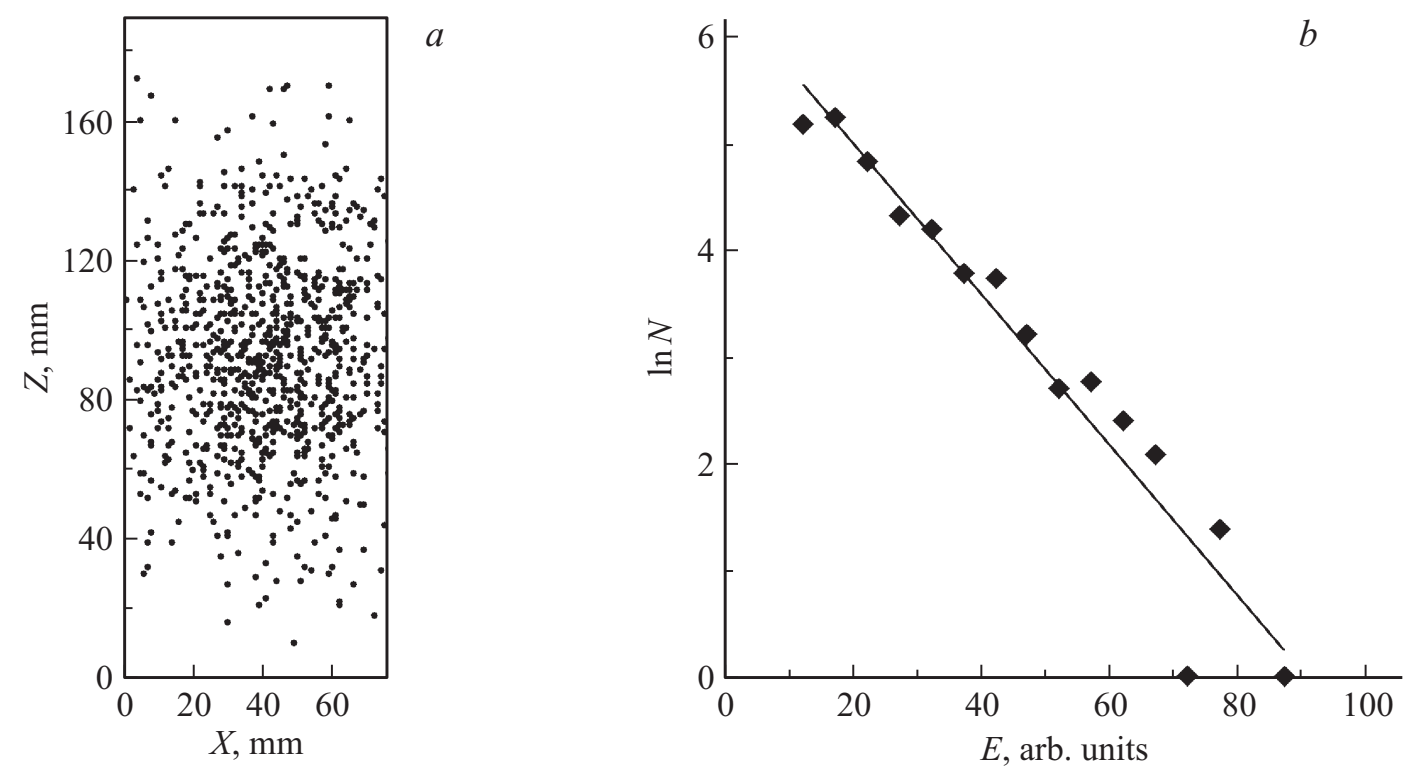

Рис. 9. Пространственный и энергетический анализ разрушения водонасыщенного образца гранита Вестерли. $a-$ проекции координат гипоцентров источников АЭ, $b$ - распределение сигналов акустической эмиссии по энергии $E$.

ванных сигналов АЭ по энергии можно с одинаковой погрешностью аппроксимировать как экспоненциальной, так и степенной функцией (рис. 10,,$c$ ). Скорее всего, этот результат указывает на различную „чувствительность“ структурно-неоднородного материала к электрическому воздействию. Пространственное сканирование образца - построение энергетических распределений сигналов АЭ для различных вертикальных зон - показало, что можно выделить пространственную область I, ограниченную по вертикали 30-50 mm (рис. 10, a), в которой распределение сигналов АЭ по энергии имеет экспоненциальный вид. В областях II $(10-30 \mathrm{~mm}$ по высоте, рис. $10, a)$ и III $(60-75 \mathrm{~mm}$, рис. $10, a)$ распределение степенное.

\section{4. Обсуждение результатов}

Эксперименты, проведенные на образцах гранита при различных условиях деформирования, показали, что 

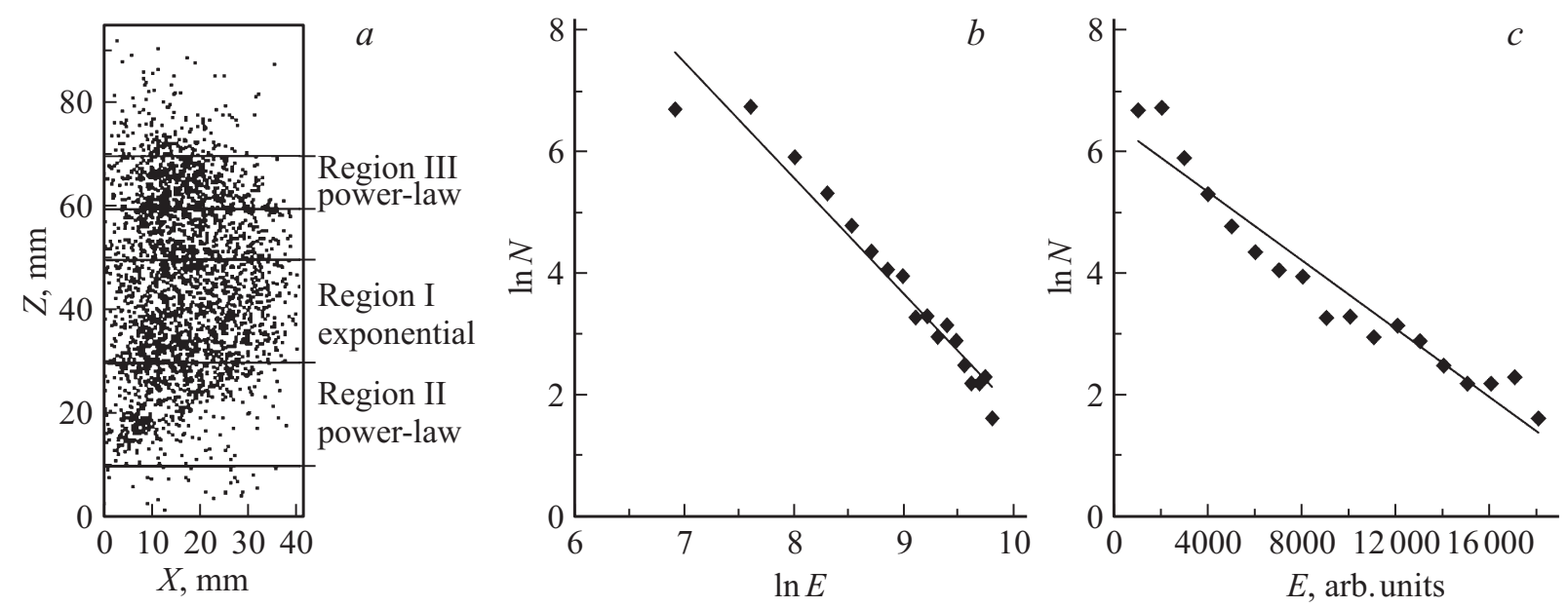

Рис. 10. Пространственный и энергетический анализ разрушения образца Мансуровского гранита, подвергнутого электрическому воздействию. Проекции координат гипоцентров источников АЭ $(a)$ и распределения сигналов акустической эмиссии по энергии $E(b, c)$.

характер накопления повреждений меняется как при изменении степени водонасыщенности образца, так и в случае наличия непрерывного воздействия слабого электрического поля. При деформировании гранита естественной влажности процесс накопления повреждений имеет стадию пространственной локализации, которая отражается в группировании гипоцентров источников АЭ в районе формирующегося очага макроразрушения. Область локализации источников АЭ характеризуется степенной формой распределения сигналов АЭ по энергии. Полученный результат не является новым, а служит дополнительной проверкой адекватности получаемых на имеющемся оборудовании результатов.

В случае сжатия гранита Вестерли с постоянным нагнетанием воды накопление повреждений имеет делокализованный характер. Причиной этого, с точки зрения авторов, может являться гидролитический механизм, который, согласно [50], значительно уменьшает энергию активации процесса разрушения. В работе [50] показано, что молекулы воды принимают активное участие в гидролитическом разрыве межатомных связей. При этом реакция гидролиза под влиянием внешнего напряжения идет даже при комнатной температуре. Энергия активации разрыва связи при таком процессе в 4 раза меньше, чем при чисто силовом, что облегчает процесс развития (укрупнения, слияния) имеющихся дефектов, которые еще до начала деформирования заполнены водой. Вода заполняет все уже имеющиеся в материале до начала нагружения дефекты типа трещин, пор, капилляров. Эти дефекты распределены дисперсно по объему образца. Образование новых дефектов (наиболее вероятно трещин) происходит при резком увеличении нагрузки, что сопровождается значительным, но кратковременным увеличением активности АЭ (рис. 8). Можно предположить, что далее в условиях постоянной нагрузки происходит заполнение этих дефектов водой, а их последующий рост также сопровождается выделением упругой энергии, однако ее уровень, по-видимому, ниже порога регистрации нашей АЭ-системы. Новые дефекты в этот период времени, скорее всего, не образуются.

Расчет поля напряжений, проведенный с помощью метода конечных элементов, показал, что коэффициент перенапряжений (т. е. отношение локального напряжения к среднему) на поверхности дефекта, заполненного водой, меньше, чем на поверхности дефекта в сухом материале. Следовательно, взаимодействие дефектов, которое определяется полем напряжений, в случае сухих и заполненных водой дефектов различно. В результате получаем сильно поврежденный материал, который разрушается при приложении меньшей нагрузки, чем в экспериментах с сухим образцом [49].

При электрическом воздействии (результирующая напряженность поля не превышает $1 \mathrm{kV} / \mathrm{m}$ ) наблюдается промежуточный (относительно описанных ранее) сценарий накопления повреждений. В результате решения задачи локации визуальная локализация гипоцентров источников АЭ не наблюдается, тогда как по виду распределения сигналов АЭ по энергии выделяется несколько пространственных областей, распределение в которых является степенным или одинаково аппроксимируется экспоненциальной и степенной функцией. Это означает, что в данных областях процесс дефектообразования приблизился или перешел к самоорганизованному критическому состоянию, для которого характерно взаимодействие между дефектами. Ранее в работе [51] на основе решения задачи о взаимодействии дефектов было предложено возможное теоретическое объяснение изменения вида энергетического распределения сигналов АЭ при приближении к моменту разрушения образца.

Наличие областей с разным характером накопления повреждений при интегральной делокализованной картине расположения источников АЭ указывает на то, 
что слабое электрическое поле по-разному влияет на различные области образца. Причины этого могут быть следующими.

1. Минеральный состав образца гранита и нерегулярное расположение минералов с различными электрическими свойствами. Действие электрического поля вызывает в кристаллитах, составляющих образец, поляризацию и появление электрического дипольного момента.

2. Вариация ориентации исходных трещин по объему образца, влияющая на степень взаимодействия трещин как электрических диполей, помогающего или препятствующего их росту.

Выявление пространственных областей, в которых происходит коррелированное дефектообразование, указывает на то, что и при электрическом воздействии процесс разрушения развивается по двухстадийному механизму (так же как и без воздействия). Возможно, именно по этой причине не наблюдается изменения прочностных свойств материала.

\section{5. Заключение}

В работе для исследования влияния состояния внутренних границ раздела на характер разрушения структурно-неоднородного композиционного материала, которым является гранит, была проведена серия экспериментов по квазистатическому сжатию гранита Вестерли с постоянным нагнетанием воды и одноосному сжатию Мансуровского гранита с воздействием слабого (по сравнению с напряженностью диэлектрического пробоя) электрического поля. Для выявления влияния внешних факторов (водонасыщения или электрического воздействия) на характер разрушения гранита полученные результаты сравнивались с результатами экспериментов по деформированию гранита Вестерли естественной влажности в условиях управляемого режима нагружения и одноосному сжатию Мансуровского гранита без электровоздействия соответственно. Авторами рассматривались такие параметры процесса накопления повреждений, как однородность распределения дефектов (источников АЭ) по объему деформируемого образца и форма распределения сигналов АЭ по энергии.

Проведенный анализ полученных экспериментальных данных показал, что изменение условий деформирования гранита - непрерывное водонасыщение в процессе нагружения или электрическое воздействие существенно влияет на картину накопления дефектов. В данных экспериментах, согласно результатам решения задачи локации источников АЭ, дефекты образуются хаотично во всем объеме образца вплоть до разрушения. Анализ функционального вида энергетических распределений сигналов АЭ позволил установить, что в случае непрерывного электрического воздействия, даже несмотря на практически равномерное по пространству накопление дефектов, в некоторых областях происходит переход к коррелированному дефектообразованию.

Однако вопрос о механизмах влияния водонасыщения или слабого электрического поля на процесс накопления повреждений, безусловно, требует дополнительных исследований.

Авторы выражают благодарность В.А. Мубассаровой за помощь в проведении экспериментов и Л.М. Богомолову за конструктивные замечания и обсуждение результатов.

\section{Список литературы}

[1] С.Н. Журков, В.С. Куксенко. Механика полимеров 10, 5, 792 (1974).

[2] В.П. Тамуж, В.С. Куксенко. Микромеханика разрушения полимерных материалов. Зинатне, Рига (1978). 294 с.

[3] D.A. Lockner, J.D. Byerlee, V. Kuksenko, A. Ponomarev, A. Sidorin. In: Fault mechanics and transport properties of rocks / Eds B. Evans, T.-F. Wong. London. Academic Press (1992). P. 3.

[4] M. Petružálek, J. Vilhelm, V. Rudajev, T. Lokajíček, T. Svitek. Int. J. Rock Mech. Mining Sci. 60, 208 (2013).

[5] М.В. Курленя, Г.Е. Яковицкая, Г.И. Кулаков. Физ.-техн. пробл. разработки полезных ископаемых 1, 35 (1991).

[6] М.В. Курленя, Г.И. Кулаков, Г.Е. Яковицкая. Физ.-техн. пробл. разработки полезных ископаемых 1, 3 (1993).

[7] Г.И. Кулаков, Г.Е. Яковицкая. Прикл. механика и техн. физика 6, 153 (1995).

[8] A.G. Vostretsov, G.I. Kulakov, Yu.A. Timonenkov, G.E. Yakovitskaya. J. Mining Sci. 34, 4, 296 (1998).

[9] В.И. Веттегрень, В.С. Куксенко, И.П. Щербаков. В сб.: $\mathrm{XX}$ Петербургские чтения по проблемам прочности, посвященные памяти проф. В.А. Лихачева. СПбГУ, СПб. (2012). Ч. 2. С. 100.

[10] В.И. Веттегрень, В.С. Куксенко, И.П. Щербаков. ЖТФ 83, 1, 144 (2013).

[11] A. Carpinteri, A. Chiodoni, A. Manuello, R. Sandrone. Strain. 47, 282 (2011).

[12] A. Carpinteri, F. Cardone, G. Lacidogna. Exp. Mech. 50, 1235 (2010).

[13] T.N. Dey, C.Y. Wang. Int. J. Rock Mech. Mining Sci. 18, 199 (1981).

[14] R.L. Kranz. Int. J. Rock Mech. Mining Sci. 16, 37 (1979).

[15] Y. Kawaguchi. Jpn. J. Appl. Phys. 37, 6A, 3495 (1998).

[16] В.Л. Гиляров, Е.Е. Дамаскинская, А.Г. Кадомцев, И.Ю. Рассказов. В сб.: XX Петербургские чтения по проблемам прочности, посвященные памяти проф. В.А. Лихачева. СПбГУ, СПб. (2012). Ч. 2. С. 140.

[17] A.S. Voznesenskii, Ya.O Kutkin, M.N. Krasilov, A.A. Komissarov. Int. J. Fatigue 77, 186 (2015).

[18] A.V. Ponomarev, A.D. Zavyalov, V.B. Smirnov, D.A. Lockner. Tectonophysics 277, 57 (1997).

[19] О.Б. Наймарк. В сб.: Физические основы прочности и пластичности. ГПИ, Горький (1985). С. 55.

[20] О.Б. Наймарк. Письма в ЖЭТФ 67, 9, 751 (1998).

[21] O.B. Naimark. In: Advances in multifield theories of continua with substructure / Ed. G. Capriz, P. Mariano. Birkhauser, Boston (2004). P. 75. 
[22] И.А. Пантелеев, О.А. Плехов, О.Б. Наймарк. Физика Земли 6, 43 (2012).

[23] M. Kachanov. Appl. Mech. Rev. 45, 8, 304 (1992).

[24] V. Kuksenko, N. Tomilin, E. Damaskinskaya, D. Lockner. Pure Appl. Geophys. 146, 2, 253 (1996).

[25] А. Карпинтери, Дж. Лачидонья, С. Пуцци. Физ. мезомеханика 11, 3, 75 (2008).

[26] Л.Р. Ботвина, И.М. Ротвайн, В.И. Кейлис-Борок, И.Б. Опарина. ДАН 345, 809 (1995).

[27] G.I. Barenblatt, L.R. Botvina. Int. J. Eng. Sci. 20, 2, 187 (1982).

[28] В.Л. Гиляров, М.С. Варкентин, В.Е. Корсуков, М.М. Корсукова, В.С. Куксенко. ФТТ 52, 1311 (2010).

[29] С.И. Шерман, К.Ж. Семинский. Геодинамика и тектонофизика 1, 4 (2010).

[30] В.С. Куксенко, Х.Ф. Махмудов, Б.Ц. Манжиков. Физ.-техн. пробл. разработки полезных ископаемых 4, 29 (2010).

[31] Е.Е. Дамаскинская, А.Г. Кадомцев. Физика Земли 3, 78 (2015).

[32] Е.Е. Дамаскинская, А.Г. Кадомцев. Письма в ЖТФ 39, 2, 29 (2013).

[33] Г.А. Соболев, А.В. Пономарев, Ю.Я. Майбук, Н.А. Закржевская, В.И. Понятовская, Д.Г. Соболев, А.А. Хромов, Ю.В. Цывинская. Физика Земли 2, 50 (2010).

[34] Г.А. Соболев, А.В. Пономарев. Физика Земли 10, 48 (2011).

[35] T. Ishido, H. Mizutani. Tectonophysics 67, 13 (1980).

[36] T. Ishido, O. Nishizawa. J. Geophys. Res. 89. B6, 4153 (1984).

[37] L. Bogomolov, A. Zakupin. Solid State Phenom. 137, 199 (2008).

[38] L.M. Bogomolov, P.V. Il'ichev, V.N. Sychev, A.S. Zakupin, V.A. Novikov, V.I. Okunev. Ann. Geophys. 47, 1, 65 (2004).

[39] В.А. Мубассарова, Л.М. Богомолов, А.С. Закупин, И.А. Пантелеев, О.Б. Наймарк. Geodynamics Tectonophysics. 5, 4, 919 (2014).

[40] Л.М. Богомолов, А.С. Закупин, В.Н. Сычев. Электровоздействия на земную кору и вариации слабой сейсмичности. LAP Lambert Academic Publ., Саарбрюккен (2011). $408 \mathrm{c}$.

[41] T. Chelidze, N. Varamashvili, M. Devidze, Z. Tchelidze, V. Chikhladze, T. Matcharashvili. Ann Geophis. 45, 5, 587 (2002).

[42] В.А. Гаврилов, И.А. Пантелеев, Г.В. Рябинин. Физика Земли 1, 89 (2014).

[43] I.A. Panteleev, V.A. Gavrilov. Rus. J. Earth Sci. 15. 4, ES4003 (2015).

[44] В.А. Гаврилов. ДАН 414, 3, 389 (2007).

[45] S.A. Stanchits, D.A. Lockner, A.V. Ponomarev. Bull. Seism. Soc. Am. 93, 4, 1803 (2003).

[46] Н.Г. Томилин, Е.Е. Дамаскинская, В.С. Куксенко. ФТТ 36, 3101 (1994).

[47] Н.Г. Томилин, Е.Е. Дамаскинская, П.И. Павлов. Физика Земли 8,69 (2005).

[48] В.Л. Гиляров, Е.Е. Дамаскинская, А.Г. Кадомцев, И.Ю. Рассказов. Физ.-техн. пробл. разработки полезных ископаемых 3, 40 (2014).

[49] А.Г. Кадомцев, Е.Е. Дамаскинская, В.С. Куксенко. ФТТ 53, 1777 ( 2011).

[50] В.А. Берштейн, В.В. Никитин, В.А. Степанов, Л.М. Шамрей. ФТТ 15, 3260 (1973).

[51] Е.Е. Дамаскинская, А.Г. Кадомцев. Вестн. Тамбов. ун-та. Сер. Естеств. и техн. науки 20, 1, 77 (2015). 